\title{
BMJ Open Effect of personalised citizen assistance for social participation (APIC) on older adults' health and social participation: study protocol for a pragmatic multicentre randomised controlled trial (RCT)
}

\author{
Mélanie Levasseur, ${ }^{1,2}$ Marie-France Dubois, ${ }^{1,2}$ Johanne Filliatrault, ${ }^{3,4}$ \\ Helen-Maria Vasiliadis, ${ }^{5,6}$ Joanie Lacasse-Bédard, ${ }^{1}$ André Tourigny, ${ }^{7,8}$ \\ Marie-Josée Levert, ${ }^{9,10}$ Catherine Gabaude, ${ }^{11}$ Hélène Lefebvre, ${ }^{9,10}$ Valérie Berger, ${ }^{12}$ \\ Chantal Eymard ${ }^{13}$
}

To cite: Levasseur M, Dubois M-F, Filliatrault J, et al. Effect of personalised citizen assistance for social participation (APIC) on older adults' health and social participation: study protocol for a pragmatic multicentre randomised controlled trial (RCT). BMJ Open 2018;8:e018676. doi:10.1136/ bmjopen-2017-018676

- Prepublication history for this paper is available online. To view these files, please visit the journal online (http://dx.doi org/10.1136/bmjopen-2017018676).

Received 14 July 2017 Revised 16 January 2018 Accepted 1 February 2018

Check for updates

For numbered affiliations see end of article.

Correspondence to Dr Mélanie Levasseur; Melanie.Levasseur@ USherbrooke.ca

\begin{abstract}
Introduction The challenges of global ageing and the growing burden of chronic diseases require innovative interventions acting on health determinants like social participation. Many older adults do not have equitable opportunities to achieve full social participation, and interventions might underempower their personal and environmental resources and only reach a minority. To optimise current practices, the Accompagnementcitoyen Personnalisé d'Intégration Communautaire (APIC), an intervention demonstrated as being feasible and having positive impacts, needs further evaluation. Methods and analysis A pragmatic multicentre, prospective, two-armed, randomised controlled trial will evaluate: (1) the short-term and long-term effects of the APIC on older adults' health, social participation, life satisfaction and healthcare services utilisation and (2) its cost-effectiveness. A total of 376 participants restricted in at least one instrumental activity of daily living and living in three large cities in the province of Quebec, Canada, will be randomly assigned to the experimental or control group using a centralised computer-generated random number sequence procedure. The experimental group will receive weekly 3-hour personalised stimulation sessions given by a trained volunteer over the first 12 months. Sessions will encourage empowerment, gradual mobilisation of personal and environmental resources and community integration. The control group will receive the publicly funded universal healthcare services available to all Quebecers. Over 2 years (baseline and 12, 18 and 24 months later), self-administered questionnaires will assess physical and mental health (primary outcome; version 2 of the 36-item Short-Form Health Survey, converted to SF-6D utility scores for quality-adjusted life years), social participation (Social Participation Scale) and life satisfaction (Life Satisfaction Index-Z). Healthcare services utilisation will be recorded and costs of each intervention calculated.
\end{abstract}

Strengths and limitations of this study

- This innovative pragmatic multicentre, prospective, two-armed, randomised controlled trial study will generate new knowledge on impacts over a 2-year period of a promising health and social intervention designed to reduce the use of healthcare services and improve the cost-effectiveness of current practices.

- The economic evaluation will help generate evidence on the cost-effectiveness of health-promoting interventions that encourage empowerment, gradual mobilisation of personal and environmental resources and community integration in older adults.

- The composition of the team, including national and international experts, will ensure a high-quality evaluative study and optimal dissemination plan that will foster replication in other sociocultural contexts.

- Although contacts between Accompagnementcitoyen Personnalisé d'Intégration Communautaire volunteers and those who work with the control group older adults will be limited as much as possible, there is potential for contamination between experimental and control groups.

- Among other possible limitations, as the presence of cognitive impairment will be based on the coordinators' judgement rather than a standardised tool, the cognitive capacities of some participants might not be sufficient to properly understand and answer the study questionnaires.

Ethics and dissemination The Research Ethics Committee of the CIUSSS Estrie - CHUS has approved the study (MP-31-2018-2424). An informed consent form will be read and signed by all study participants. Findings will be published and presented at conferences. Trial registration number NCT03161860; Pre-results. 


\section{INTRODUCTION}

Social participation is critical to promote health, prevent disabilities and foster health equity in older adults and societies ${ }^{1}$ but is restricted for approximately half of older Canadians. ${ }^{2}$ Social participation is defined as the involvement of a person in activities that provide him or her with interactions with others in the community. ${ }^{3}$ These include social and leisure activities, such as doing physical exercises, visiting friends and volunteering, that meet fundamental needs for interaction and self-accomplishment. ${ }^{4}$ While optimal social participation is often associated with greater community integration, at the other end of the continuum, social isolation often involves living alone, having a small social network and infrequent social contacts. ${ }^{5}$ Although, in the objective state of social isolation, a person may be isolated but prefer to be alone, in the subjective emotional state of loneliness, a person may have a good social network and participate socially but feel alone. ${ }^{56}$ A meta-analysis of 148 longitudinal studies (309000 participants) demonstrated that individuals integrated into their community had half the risk of dying within 7 years than those who lived a more solitary life. ${ }^{7}$ This protective effect is even greater than stopping smoking, vaccination, doing physical exercises, losing weight, taking hypotensive medication and breathing clean air. Although broadly targeted by community organisations, health professionals and municipalities, few effective social participation interventions really reach vulnerable populations and are implemented in practice. ${ }^{8}$

According to the 41 promising interventions to promote social participation that were evaluated, ${ }^{9-11}$ including evidence from systematic reviews, ${ }^{12}{ }^{13}$ it is possible to improve self-rated health, well-being and social participation, slow cognitive and functional decline and decrease medication use and depressive symptoms in older adults. ${ }^{9-11}{ }^{14-16}$ However, among the interventions identified, only two concerned persons with disabilities, but they did not involve collaboration with community resources and were narrow, that is, focused on involvement in healthcare decision making ${ }^{17}$ or restoration of a social network. ${ }^{18}$ Other interventions with volunteers targeted specific daily activities (eg, medical appointments or shopping) or physical and cultural activities to reduce loneliness. ${ }^{19}$ Moreover, these interventions respectively resulted more in facilitation of daily activities than older adults' empowerment and community integration, ${ }^{9}$ without clearly considering the effects on social participation. ${ }^{11}$ Interventions were also carried out in a group setting, without necessarily considering older adults' interests and needs. ${ }^{16}$ Previous studies emphasised the importance of and need for social interventions to foster empowerment, support the development of significant relationships and activities, be personalised and last at least 6 months in order to be effective. ${ }^{12}{ }^{13}$ To our knowledge, eight ${ }^{20-27}$ randomised controlled trials (RCTs) rigorously evaluated the impact of social participation interventions, but none specifically involved older adults with disabilities. The majority $(n=5 ; 62.5 \%)$ were carried out in the USA, with more than a thousand older adults (median $=154$; range $=32-582$ ) living in the community $(n=6 ; 75.0 \%)$. All trials aimed to evaluate the impact or effectiveness of the interventions and one ${ }^{21}$ also documented the service delivery process. Among RCTs on similar interventions with older adults with or without disabilities, Lifestyle Redesign, ${ }^{28}$ comprising $6-9$ months of preventive occupational therapy group and individual sessions empowering older adults to regularly perform healthy and fulfilling activities, has been shown to benefit physical and mental health and be cost-effective. ${ }^{29}$

Based on a logic model including theoretical background from an ecological systemic model, ${ }^{30}$ positive psychology $^{31}$ and occupational science ${ }^{32}$ and recently adapted for older adults with disabilities, preliminary studies demonstrated the feasibility ${ }^{33}$ and positive impacts $^{34}$ of the personalised citizen assistance for social participation (Accompagnement-citoyen Personnalisé d'Intégration Communautaire (APIC)), a personalised intervention focusing on community integration. The APIC involves a non-professional attendant who, after $2-5$ days of training, provides a stimulation session of 2-3 hours each week over a period of 6-18 months targeting significant social and leisure activities that are otherwise difficult for older adults to accomplish. Two qualitative studies demonstrated that this intervention increases accomplishment of and satisfaction with social and leisure activities among 9 adults ( 4 women) $)^{35}$ and 11 older adults (7 women $)^{36}$ with traumatic brain injury. The APIC helped them engage in constructive reflections about their lives and improve their well-being. Moreover, using mixedmethod concurrent triangulation ${ }^{37}$ including a pre-experimental design, an adapted version of the APIC for older adults with disabilities demonstrated feasibility ${ }^{33}$ and increased mobility, accomplishment of social activities and frequency of leisure activities among 16 older adults (11 women). ${ }^{34}$ Complementing professional healthcare services by fostering links with the community and extending services over time, the APIC helped older adults with disabilities resume, maintain, explore and experiment with significant social activities. The APIC seemed to increase their psychological and physical wellbeing, feeling of control, connectedness, self-esteem and motivation to accomplish activities. Such connectedness and accomplishment might in turn reduce loneliness and social isolation.

Although promising, the APIC needs further study. First, in previous studies, the APIC was introduced and supported by the research team, and attendants were paid. These previous studies were carried out in different conditions than the usual care settings where community organisations will be responsible for setting up the intervention. In the usual settings, the attendants will be volunteers supervised by paid coordinators and healthcare professionals. As things stand at this time, many thousands of older adults receive friendly visits from volunteers, without being explicitly empowered to use 
their personal and environmental resources. In addition, older adults are not appropriately stimulated to participate in the community. Moreover, as previous studies used qualitative or pre-experimental designs, studies demonstrating higher levels of evidence are needed to verify the impacts of the APIC on health, social participation and life satisfaction. This research should also be carried out with larger samples and include more men since previous studies found gender differences in social participation; for example, older women are more likely to participate in community activities than men, except for sports and physical activities. ${ }^{38}$ In fact, social participation needs of women and men differ, ${ }^{39-41}$ and women have greater social connectivity than men. ${ }^{42}$ Hence, particular attention must be paid to gender in the recruitment, intervention and data analysis phases. Finally, future studies also need to consider the cost of the intervention and its effectiveness in reducing the use of healthcare services. With current public funding constraints, such a cost-effectiveness analysis, from perspectives of older adults, healthcare system and societ, constitutes critical information for decision makers. ${ }^{43}$ In summary, more studies are needed to provide community organisations with an intervention that efficiently promotes the health and social participation of community-dwelling older adults.

\section{Trial objectives and hypothesis}

This study aims to evaluate: (1) the short-term and longterm effects of the APIC (respectively 0, 6 and 12 months after the end of the intervention) on older adults' physical and mental health, social participation, life satisfaction and healthcare services utilisation and (2) its cost-effectiveness. In parallel, the implementation of the APIC, including factors facilitating and impeding it, will be documented. Concerning the first two objectives, two hypotheses are formulated: (1) the APIC will prevent a decline in older women's and men's health, social participation and life satisfaction and reduce their use of healthcare services and (2) the APIC will be associated with lower costs, from perspectives of older adults, healthcare system and society, including healthcare expenditures and other costs and higher quality-adjusted life years (QALY).

\section{METHOD AND ANALYSIS}

\section{Study design and setting}

To achieve these objectives, a pragmatic multicentre, prospective, two-armed, RCT in accordance with extended Consolidated Standards of Reporting Trials (CONSORT) statements ${ }^{44}$ will be carried out. An RCT is justified to rigorously evaluate the APIC's impacts on older adults' health (primary outcome), social participation, life satisfaction and health services utilisation and its cost-effectiveness. As the intervention ultimately aims to reduce healthcare costs and improve physical, mental and social well-being, not just the absence of disease, ${ }^{45}$ health was identified as the primary outcome.
Following a call for applications, five non-profit community organisations located in three cities in Quebec, Canada, namely Montreal (3), Drummondville (1) and Quebec City (1), were selected to deliver the intervention. To be selected, these organisations had to provide direct activities and services designed to reduce social isolation and loneliness and foster health and well-being. They were currently providing direct services to thousands of older adults (median=637; range $=325$ to 4512 ). They also had to have expertise in managing projects and volunteers and the capacity to engage the community and create partnerships and be supported by a Health and Social Services Center (HSSC). In addition, each organisation has or will hire a coordinator with experience in managing projects and volunteers. These five coordinators will be specifically trained to recruit participants, enrol volunteers, assign participants to volunteers, gather informed consent, supervise baseline testing, train the volunteers and coordinate the intervention. Consistent with $\mathrm{RCTs}^{46}{ }^{47}$ this training will underscore the importance of addressing participants' concerns, making it impossible to modify group assignment and avoiding technical terms such as 'trial' and 'randomisation'. To address participants' concerns, a guide including potential questions will be developed for coordinators. Finally, all volunteers will undergo a criminal record check.

\section{Participants}

Similar to older adults already served by community organisations, participants will have to: (1) be aged 65 years or older, (2) live at home or in seniors' residences, that is, private nursing homes for people with and without disability, (3) be restricted in at least one basic or instrumental activity of daily living (ADL) and (4) have a good understanding of French or English. Restriction in ADL will be identified according to a checklist of 10 activities (walking, standing, getting in and out of bed, washing, dressing, taking medication, going up or down stairs, transporting objects, shopping and house cleaning). ${ }^{48}$ These activities are considered restricted if performed with difficulty or if help is required. Personal factors (pain or discomfort that restricts the accomplishment of activities as well as vision and hearing impairments, even if the person has a technical device) and home care services received will also be considered in those restrictions. Based on the coordinators' judgement and to ensure that participants understand the questionnaires, older adults presenting moderate to severe cognitive impairments will be excluded.

\section{Recruitment}

Since older women and men have different social participation needs, various strategies will be used to recruit both genders as equally as possible. Considering the particular context of each community, strategies will involve the internet, newspapers, radio or print notices, membership and waiting lists of community organisations, community-based activities (eg, open houses), meals-on-wheels, 


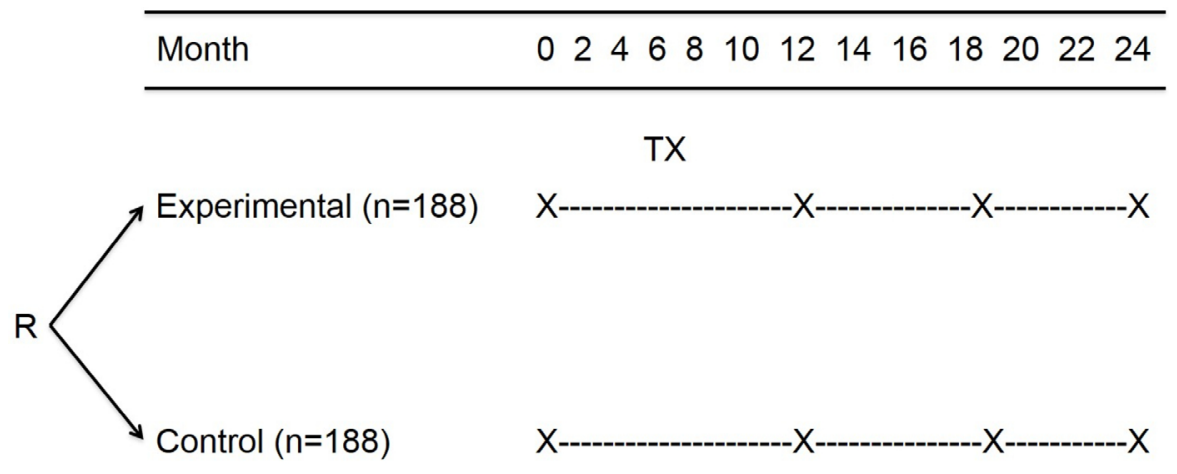

Figure 1 Study design. R, randomisation; X, assessment, TX, treatment (APIC). APIC, Accompagnement-citoyen Personnalisé d'Intégration Communautaire.

family physicians and clinicians and outreach work. Recruitment will also target various settings, that is, health or seniors' activity centres, religious congregations, seniors' residences and low-cost housing. In the early stages of the study, regular monitoring will ensure effective strategies to reach older adults.

All older adults who potentially meet the eligibility criteria in the recruitment phase of the study, starting in October 2017, will be invited to participate consecutively, that is, as they are contacted by the organisation and until the sample size is reached (screening log). If they are interested in participating, the coordinator will meet face to face with them to discuss the project and explain that they may or may not be assigned to the experimental group. If they meet the eligibility criteria, the information and consent form will be read, discussed and signed. Once written informed consent is obtained, older adults will complete the baseline self-administered questionnaires. The coordinators will verify full completion and send the forms to the research team.

Older adults who decline to participate will, if they agree, be asked for some sociodemographic information, that is, age, gender and living situation, and reason for not participating. This information is needed to compare participants and non-participants and to document the reasons for non-participation in the intervention.

\section{Randomisation}

After completion of the baseline questionnaires, the coordinators will reveal if the participant was randomly assigned to the experimental (APIC) or control group (figure 1) according to the Research Electronic Data Capture system. ${ }^{50}$ This centralised computer-generated random number sequence procedure, which cannot be modified, will stratify the randomisation according to the five community organisations and living alone versus not. The coordinator will then inform participants of their group assignments verbally and with a handout explaining the implications and time points for data measurements. Date and time of randomisation and completion of baseline questionnaires will be documented to ensure sequential enrolment.

\section{Blinding}

Due to the type of intervention, coordinators, volunteers and participants will not be blinded to the interventions. However, they will not be informed of the study hypotheses. As the study uses self-report questionnaires, no assessors are required. Research assistants involved in data collection (see relevant section below) and the statistician responsible for the analysis will be blinded to the intervention until completion of the study.

\section{Intervention}

Older adults in the experimental group (APIC; figure 2) will receive, over a 12-month period, weekly 3-hour personalised stimulation sessions given by an attendant, that is, a specially trained volunteer. During the sessions, the attendant will encourage the older adult to set goals, mostly concerning social and leisure activities that are important to him or her. As it is personalised and the content and format are designed for both older women and men, the intervention will foster the interest and engagement of both genders. To appropriately encourage them, the attendant must listen to the older adults and understand their needs and specific context. Doing social and leisure activities with the attendant's support will allow older adults to gradually mobilise their personal and environmental resources and become more independent and satisfied with their community integration. For example, the attendant can encourage the use of the person's planning abilities or social participation opportunities in the environment. In addition to focusing on their specific needs and interests according to their life context, this intervention is intended to empower older adults and build on their strengths and skills.

\section{Attendants' training}

Attendants will participate in a face-to-face 1 day 6 hour training session addressing the following topics: (1) 


\begin{tabular}{|c|c|c|c|}
\hline Theory and Core components of APIC & $\begin{array}{l}\text { Intervention Delivery } \\
\text { Methods (Personalised) }\end{array}$ & $\begin{array}{l}\text { Dynamic Change in Social and } \\
\text { Leisure Activities }\end{array}$ & $\begin{array}{l}\text { Health-Related } \\
\text { Outcomes }\end{array}$ \\
\hline $\begin{array}{l}\text { Theoretical models underlying the } \\
\text { Intervention } \\
\text { - Ecological Systemic Model } \\
\text { - Positive Psychology } 31 \\
\text { - Occupational science } \\
\text { Core component of APIC } \\
\text { 1. Attendant Trained and } \\
\text { 2. Supervised } \\
\text { Changes } \\
\text { 3. Personalised } \\
\text { 4. Fosters Empowerment } \\
\text { 5. Centered on Life Projects } \\
\text { *Supervision of Attendants to Ensure } \\
\text { Appropriate Empowerment and } \\
\text { Community Integration of Older } \\
\text { Adults }\end{array}$ & $\begin{array}{l}\text { Intervention delivery } \\
\text { methods } \\
\text { 1. Reflection and } \\
\text { Discussion to Set } \\
\text { Goals with Help of } \\
\text { Attendant } \\
\text { 2. Direct Experience, } \\
\text { i.e. Accomplishment } \\
\text { of Social and Leisure } \\
\text { Activities } \\
\text { 3. Personal Exploration }\end{array}$ & 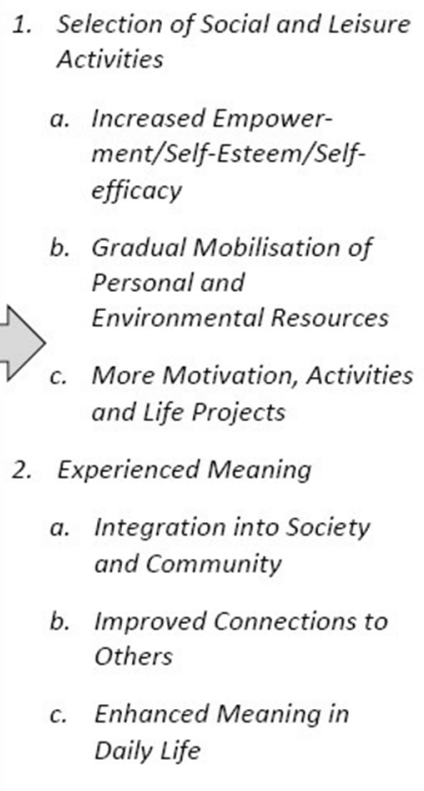 & $\begin{array}{l}\text { 1. Enhanced } \\
\text { Physical Health } \\
\text { 2. Improved } \\
\text { Mental Health } \\
\text { 3. Increased } \\
\text { Social } \\
\text { Participation } \\
\text { 4. Greater Life } \\
\text { Satisfaction }\end{array}$ \\
\hline
\end{tabular}

Figure 2 Personalised citizen assistance for social participation (APIC) logic model.

core components underlying the intervention, (2) roles, mentoring and tools, (3) process to help older adults set goals for accomplishing social and leisure activities and empowerment, (4) knowledge about people with disabilities and (5) knowledge about social and leisure activities available in the community. Each attendant will also be given an attendant's guide including information on these topics.

This training will be supplemented with online video presentations focusing on knowledge about specific disabilities, for example, mild cognitive, visual or mobility impairments. These narrated PowerPoint presentations will also remind the attendant how to help older adults set goals for accomplishing social and leisure activities.

To evaluate implementation fidelity and monitor APIC attendance and for their own supervision, each week attendants will record in a semistructured diary template the date and length of visits and, if known, reasons for missing a visit. In this diary, attendants will also record the content of the visit, that is, reflections on life projects based on interests and needs, activities done or planned, as well as facilitating and impeding factors. Attendants will be encouraged to record their feelings and concerns, which will enable the coordinator to support them in complex situations. The diary will also allow coordinators to monitor adherence to the intervention and provide further assistance and training to attendants when required. Each month, attendants will also participate in a support and training meeting with a healthcare professional (occupational therapist, social worker or specialised educator) and the coordinator. These meetings will involve sharing successes, addressing difficulties and training to prepare the end of the intervention. If needed, coordinators will also organise individual contacts or meetings to help attendants resolve difficulties.

\section{Control group}

According to their specific needs and situation, the control group will receive the usual publicly funded healthcare services available to all residents of Quebec (eg, outpatient contacts with physicians and ambulatory emergency department visits, rehabilitation and inpatient stays). At the end of the study, participants in the control group will be offered the APIC.

\section{Outcomes}

Five self-report questionnaires will be used at baseline and, except for the sociodemographic variables, after the intervention is completed (12, 18 and 24 months later) to evaluate the short-term and long-term effects of the intervention on primary (health) and secondary (social participation, life satisfaction and healthcare services utilisation) outcomes and to describe the participants (table 1).

\section{Primary outcomes}

Physical and mental health will be estimated with version 2 of the 36-item Short-Form Health Survey (SF-36) ${ }^{51}$ which includes eight domains. Using algorithms, physical and mental components are calculated from the eight scales. ${ }^{52}$ Scores range from 0 to 100 , with a higher score indicating better health. ${ }^{53}$ Widely used in studies, ${ }^{54}$ the SF-36 has norms (mean=50; $\mathrm{SD}=10$ ) and good psychometric properties, including with older adults. ${ }^{55}$ For example, Gandek et $a l^{56}$ demonstrated good internal consistency (Cronbach's $\alpha$ from 0.83 to 0.93 for the eight 
Table 1 Outcomes, measures and time points

\begin{tabular}{lllll}
\hline Outcome (measures) & $\mathbf{T}_{0}$ (baseline) & $\begin{array}{l}\mathbf{T}_{1} \text { (12 months) } \\
\text { postintervention }\end{array}$ & $\begin{array}{l}\mathbf{T}_{2} \text { (18months) } \\
\text { follow-up }\end{array}$ & $\begin{array}{l}\mathbf{T}_{3} \text { (24 months) } \\
\text { follow-up }\end{array}$ \\
\hline $\begin{array}{l}\text { Physical and mental health (36-item Short-Form } \\
\text { Health Survey)* }\end{array}$ & $\sqrt{ }$ & $\sqrt{ }$ & $\sqrt{ }$ & $\sqrt{ }$ \\
$\begin{array}{l}\text { Healthcare costs } \\
\begin{array}{l}\text { Use of healthcare services (convert into } \\
\text { healthcare expenditures) }\end{array}\end{array}$ & $\sqrt{ }$ & $\sqrt{ }$ & $\sqrt{ }$ \\
$\begin{array}{l}\text { Circumstances associated with other costs } \\
\text { (participants' out-of-pocket and indirect costs } \\
\text { including caregivers' costs and lost productivity) }\end{array}$ & $\sqrt{ }$ & $\sqrt{ }$ & $\sqrt{ }$ \\
$\begin{array}{l}\text { Social participation (Social Participation Scale) } \\
\text { Life satisfaction (Life Satisfaction Index-Z) }\end{array}$ & $\sqrt{ }$ & $\sqrt{ }$ & $\sqrt{ }$ & $\sqrt{ }$ \\
\begin{tabular}{l} 
Sociodemographic variables (home questionnaire) \\
\hline
\end{tabular} & $\sqrt{ }$ & $\sqrt{ }$ & $\sqrt{ }$ & $\sqrt{ }$ \\
\hline
\end{tabular}

*Primary outcome.

domains, and 0.94 and 0.89 for the physical and mental components, respectively). In addition, this questionnaire presents good test-retest reliability, even for testing after 6 months (correlation coefficients from 0.60 to 0.90 , except for bodily pain $(0.43)) .{ }^{53}$ Finally, the SF-36 is sensitive to change, ${ }^{57}$ with a difference of 5 points in scale scores being clinically significant, as suggested by Ware $e t a l .58$

\section{Secondary outcomes}

Use of healthcare services will be recorded on a standardised questionnaire adapted from previous studies. ${ }^{59}$ This questionnaire includes 14 questions covering visits to medical and health professionals in hospital, at the office or at home, hospitalisation or inpatient rehabilitation, outpatient tests, home care and caregiver costs. For each service used, details regarding the frequency, time period and cost will be collected.

Social participation will be measured with the Social Participation Scale, ${ }^{60}$ a questionnaire that considers the frequency of accomplishment in 1 month of 10 social and community activities. Answers are transformed into a number of days, with the total score representing the sum of days of activities in 1 month. This instrument has good internal consistency (Cronbach's $\alpha$ from 0.85 to 0.91 ) with older adults living in an urban setting. ${ }^{61}$

Developed specifically for older adults, the Life Satisfaction Index-Z (LSI-Z) ${ }^{62}$ includes 13 items that explore five components of life satisfaction. Using a three-point scoring system, the score ranges from 0 to 26 , with a higher score indicating greater satisfaction. ${ }^{62}$ The LSI-Z presents moderate criterion validity with a longer version of the tool (correlation coefficient $=0.57$ ) and good internal consistency (Cronbach's $\alpha$ of 0.79 ). ${ }^{62}$

Sociodemographic variables will include gender, education, marital status, place of birth and annual family income.

\section{Economic evaluation}

The SF-36 scores will be converted to the Short-Form Six-Dimension (SF-6D) utility scores for the QALY calculation, which will identify the mean health benefits of the APIC for participants. The economic evaluation will include healthcare system costs for health services received and other indirect costs for travelling and time spent during programme and medical visits, as well as productivity losses and caregiver costs. For example, for each participant, caregiver costs such as paid and unpaid inhome support for shopping, laundry, housekeeping or cooking or assistance in making doctor appointments ${ }^{59}$ will be calculated using predetermined fees. ${ }^{6364}$ These costs will be calculated from older adults, healthcare system and societal perspectives. Intervention costs of the experimental group will be calculated based on the total funding attributed to organisations and will consider contacts and time spent with participants, preparation and travel time/fee for coordinators and volunteers. ${ }^{28}{ }^{59} \mathrm{No}$ programme-related costs will be attributed to the control group.

\section{Implementation}

A process evaluation will be used to assess fidelity and quality of implementation, clarify causal mechanisms and identify contextual factors associated with variations in outcomes. ${ }^{65-67}$ In addition to APIC attendance rates recorded in the attendant's diary, a fidelity questionnaire will be completed every 2 months by each coordinator. This questionnaire will document adherence to the intervention, that is, extent to which coordinators' actions are carried out as planned ${ }^{6568}$ and essential components of the APIC are implemented. The fidelity questionnaire includes 24 questions answered on a 4-point Likert scale. This questionnaire has been demonstrated to be a feasible, reliable and valid measure of fidelity implementation. ${ }^{69}$ Factors facilitating or impeding the implementation will also be explored with coordinators and the primary research assistant using semidirected interviews 


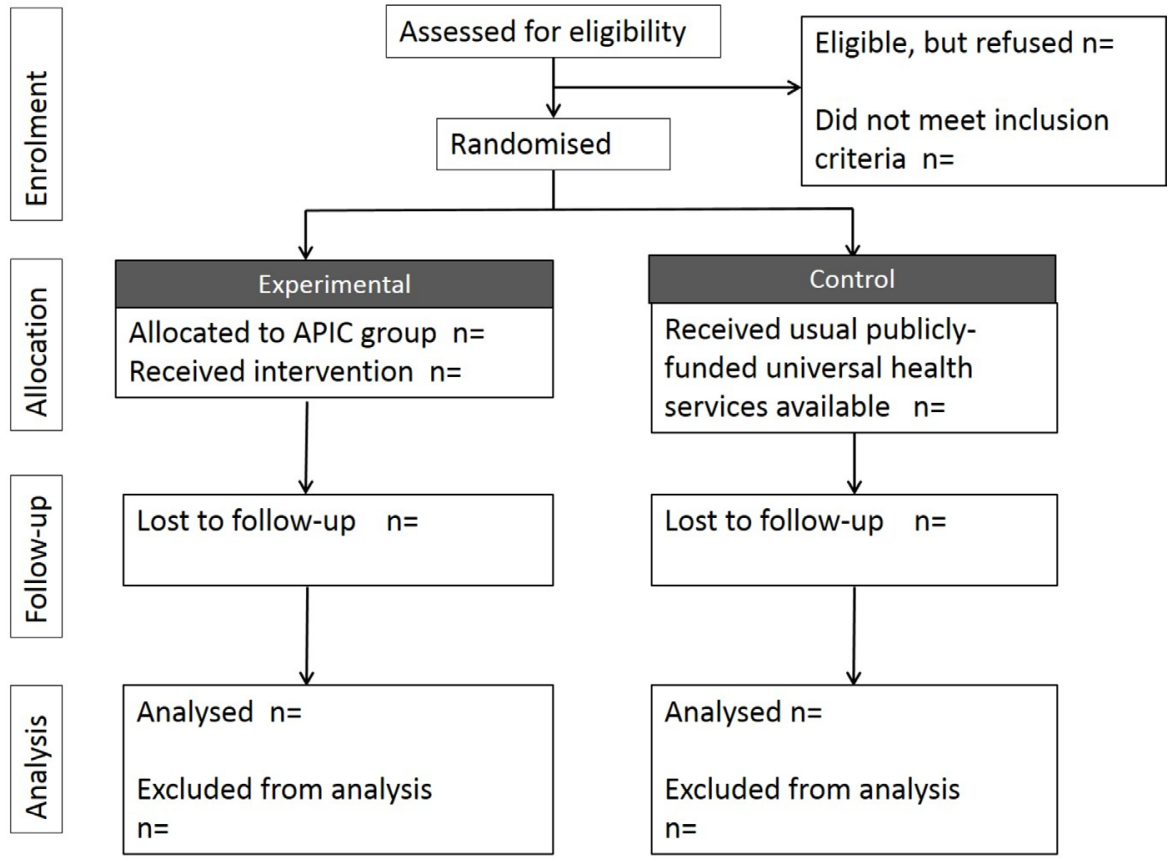

Figure 3 Trial Consort flow diagram. APIC, Accompagnement-citoyen Personnalisé d'Intégration Communautaire.

at 6 and 12 months after the beginning of the implementation and during each bimonthly meeting. This exploration will consider the context of the different community settings, including opportunities and constraints, and document differences between planned and delivered interventions.

\section{Sample size}

Each community organisation will recruit 75 older adults for a total of 376 participants. Based on similar RCTs ${ }^{28} 70$ and anticipating an attrition rate of 20\% (Trial Consort flow diagram; figure 3), a sample size of 188 per group (150 per group at the end of the study) will detect an effect size of 0.325 in the primary outcome between groups with a power of $80 \%$ and a two-sided $\alpha$ error of $5 \% .{ }^{71}$ Although, due to limited budget and feasibility considerations, it was not possible to consider gender in the sample size calculation, gender interaction will be explored (see below). An effect size of this magnitude is consistent with studies of similar social interventions. ${ }^{28}{ }^{70}$ As the SD of differences in change scores can be expected to vary between 14 and 20 points across SF-36 subscales, ${ }^{70} 72$ this effect size corresponds to group differences of $4.6-6.5$ points, which is considered a clinically important difference. Feasibility in reaching this sample size is based on previous APIC studies that recruited $71.4 \%$ and $59.3 \%$ of older adults, respectively, in a research setting ${ }^{34}$ and in one rural community organisation. ${ }^{73}$ As they might assist more than one older adult, it is anticipated that 150-175 attendants (30-35 per organisation) will be required.

\section{Data collection}

As mentioned, coordinators will hold initial face-to-face meetings lasting approximately $45 \mathrm{~min}$ with all participants that will include supervising completion of the baseline questionnaires. Ideally, the APIC will begin within 1 month and as soon as possible after the baseline measures. This strategy aims to avoid the loss of participants (death and withdrawal of consent) between randomisation and the beginning of the intervention.

Following the intervention, 12 (T1), 18 (T2) and 24 (T3) months after baseline, participants will complete the same outcome questionnaires (table 1) that will be mailed to them with a stamped return envelope. If the questionnaires returned have missing or incongruent data, the research assistant will call the older adults to complete or verify the answers. If the questionnaires are not received within 2 weeks, the research assistant will call the older adults to offer them extra time or the option to complete the questionnaires over the phone. If the questionnaires are still not received within a further 2 weeks, the research assistant will call the older adults again to offer them the option to complete the questionnaires over the phone. These strategies reduce missing data or undue data collection delays. Moreover, to recognise their time and involvement, and encourage retention in the study, participants will receive $\$ 10$ financial compensation at each measurement time.

Finally, to record the use of healthcare services, telephone interviews lasting approximately $15 \mathrm{~min}$ will be conducted by trained research assistants with all participants every 2 months throughout the 2-year period of the study. To lessen recall bias, participants will be encouraged to use a calendar to record their use of healthcare services and be asked to use this calendar during the interviews. Assisted self-report of health services use by older adults through phone calls every 2 months is reliable. ${ }^{74}$ 


\section{Data analysis}

Descriptive statistics will be used to describe the participants and document implementation fidelity, including attendance rates as well as adherence to the protocol, that is, the difference between planned and delivered interventions. Since outcomes will be measured four times (baseline, 12, 18 and 24 months later), a multilevel model for change (growth model) will be used to evaluate and compare the effectiveness of the interventions by comparing both the primary (health) and secondary (social participation, life satisfaction and healthcare services utilisation) outcomes at different timepoints and between groups while adjusting for the two stratification factors (community organisation and living alone vs not). ${ }^{75}$ All analyses will be based on the intention-totreat principle. and growth modelling will handle missing outcomes by using all available data from each older adult, even those who do not participate in all measurements. If the number and characteristics of losses to follow-up are generally unbalanced between the groups, sensitivity analyses will be conducted to see how consistent the results are across different methods to handle missing data.

The economic evaluation from the societal perspective will be based on the incremental cost-effectiveness ratio, which will be calculated as the average total difference in costs, divided by the difference in QALYs between the experimental and control groups. ${ }^{76}$ For the incremental 2-year total cost estimates, general linear models (GLM) with the best link function and family distribution ${ }^{77}$ will be used. The 2-year QALYs will be calculated with the utility scores obtained from the SF-6D [QALY=lifeyear (duration)*utility (morbidity) in that health state]. ${ }^{43}$ GLM will also be carried out to test for differences (ie, $\beta$ estimates) in QALYs between the two study arms while controlling for sociodemographic variables and assessing impacts of gender on outcomes by testing the interaction terms [gender*study arm, gender*compliance rates]. These analyses will be carried out at the end of data collection, in intention-to-treat and considering gender. To ensure quality and limit bias, a statistician will manage and analyse the data. CIs for the cost-effectiveness ratio will also be calculated by using the bootstrap method with 1000 replications. To inform decision makers on best value for money invested, cost-effectiveness acceptability curves with varying amounts of willingness to pay $(\lambda)$ will be calculated as described by Hoch and colleagues. ${ }^{77}$

All the quantitative analyses will be conducted by a statistician blind to the group allocation using SAS V.9.4 and in accordance with CONSORT standards and overseen by the methodological research committee.

To document facilitating and impeding factors and evaluate differences between planned and delivered interventions, interview transcripts and attendants' diaries will be analysed with thematic content analysis and mixed extraction grids ${ }^{78}$ using NVivo V.10 (QRS International, Doncaster, Victoria, Australia). The content of interview transcripts and diaries will be divided into units of sense, organised and reformulated in the disciplinary language and synthesised into themes. These themes will represent facilitating or impeding factors as well as essential components of the implementation. Interview transcripts and attendants' diaries will be exhaustively analysed by one research assistant to reach consensus for one third of the data cocoded by researchers. Correlation coefficients will also explore associations between attendance rates and fidelity score, on the one hand, and outcomes, on the other hand, at 12 months. Finally, facilitators, barriers and essential conditions for successful implementation, along with the effects of the intervention on older adults' health, social participation and life satisfaction, will also be examined according to gender; that is, gender effects will be considered in the qualitative and quantitative analyses described above.

\section{TRIAL MANAGEMENT AND MONITORING}

An interdisciplinary committee involving six researchers, two clinicians, two healthcare service administrators, the five administrators of the participating community organisations, two community citizens (patient partners and family members) as well as one research assistant will ensure the study progresses as planned. The committee will hold four recorded statutory meetings each year, contributing to implementing the APIC, participating in training and supporting coordinators and organisations. Biweekly phone contacts with the coordinators and bimonthly meetings will involve supervision of strategies and actions of community organisations to ensure recruitment of participants and proper delivery of the intervention. As recruitment of both older adults and volunteers is among the anticipated challenges, a communication plan including various and gradual strategies is provided and will be adapted to the needs of each organisation. If required, a sixth organisation will be involved to reach the sample size. To avoid contamination, attendants will volunteer only with older adults in the experimental group. Coordinators, attendants and participants in the experimental group will be asked not to share information about the APIC with other volunteers or older adults. Finally, biannual visits to the study sites will be carried out to monitor progress in accordance with the planned intervention. These visits will also enable one research assistant and the principal investigator to verify that participants' rights are protected and that data collected are accurate and complete.

\section{ETHICS AND DISSEMINATION}

In accordance with the Declaration of Helsinki, ${ }^{79}$ every participant will give written, free and informed consent.

Potential harms for participants include the possibility of feeling tired, uncomfortable or emotional during personalised sessions with attendants. These situations will be reported in the diary completed each week by the attendants, allowing the coordinator to react quickly if needed. Attendants are sensitised and advised to inform 
the coordinator who, with the support of the HSSC, has the expertise to handle this type of situation. If needed and desired, the older adult will be referred to a health professional.

At the end of the study, if the study demonstrates positive effects of the APIC on older adults' health, social participation, life satisfaction or healthcare services utilisation, control group participants will be offered the APIC. Following a dissemination plan, findings of this multicentre study will be published in peer-reviewed journals in the field of healthcare outcomes, community integration or health economics. Conferences targeting various audiences, for example, healthcare professionals and community organisations at the local, national and international level, are also planned. Finally, an APIC implementation guide will be disseminated.

\section{DISCUSSION}

This large scale community-based study will evaluate: (1) the short-term and long-term effects of the APIC on older adults' health, social participation, life satisfaction and healthcare services utilisation and (2) its cost-effectiveness. The underlying trial proposes to compare, over a 2-year period, a novel health-promoting intervention involving weekly 3-hour personalised stimulation sessions encouraging empowerment, gradual mobilisation of personal and environmental resources and community integration, to the usual publicly funded universal healthcare services available to all Quebecers. Previously introduced and supported by the research team, with paid attendants and a limited number of older adults, the APIC in the present study will be carried out with a larger sample and be delivered by community organisations in 'real world contexts' and in partnership with HSSCs. Like previous RCTs on Lifestyle Redesign, ${ }^{28} 7072$ the current study will generate new knowledge on the short-term and long-term effects of the APIC on health outcomes and its cost-effectiveness, including comparison of healthcare costs between the experimental and control groups.

Demonstrated as being feasible ${ }^{33}$ and having positive effects, ${ }^{34}$ the APIC has a high potential to improve health, social participation and life satisfaction among older adults, reduce the use of healthcare services and improve the cost-effectiveness of current practices. As the impact on health and use of healthcare services of social interventions targeting older adults remains unclear, ${ }^{15}$ results from this effectiveness and cost-effectiveness study, using the gold standard method to evaluate the effects of an intervention, will provide rich data about economic aspects according to the implementation of the APIC in different sociocultural contexts. ${ }^{66}$ With current public funding constraints, such a cost-effectiveness analysis, from perspectives of older adults, healthcare system and society, constitutes critical information for decision makers. ${ }^{43}$ As the APIC is a complex social intervention $^{66}$ with outcomes influenced by the intervention itself as well as the participants' characteristics, results concerning its implementation, that is, how and in which context the intervention is provided by attendants and what the response from older adults is, will generate important new knowledge.

Findings of this pragmatic trial evaluating both the shortterm and long-term effects of the APIC and its cost-effectiveness are expected to enrich current practices ${ }^{80}$ and have great potential for concrete and positive individual and societal benefits. An intersectoral team, including national and international experts, will ensure the high quality of this pragmatic multicentre, prospective, two-armed RCT. Among possible limitations and like other trials involving social interventions, blinding to group allocation will not be possible ${ }^{81}$ for older adults, coordinators and attendants. To minimise the probability of ascertainment bias, trial management and monitoring will involve supervisory mechanisms including biweekly phone contacts and bimonthly meetings with coordinators. These mechanisms will also target possible contamination bias recognised in the discussions and reduced by identifying strategies. One of these strategies is to ensure that attendants volunteer only with older adults in the experimental group. Coordinators, attendants and participants in the experimental group will also be asked not to share information about the APIC with other volunteers or older adults. As the APIC takes place in the participants' homes or community according to the older adults' needs and interests, the probability of contamination is reduced. For feasibility and pragmatic reasons, the presence of cognitive impairment in the older participants will be based on the coordinators' judgement in the initial face-to-face meeting rather than with a standardised tool, a possible limitation of this study in regard to respecting exclusion criteria and generalisation of results. Although older adults with cognitive impairment may benefit from the intervention and coordinators will all have significant experience with older adults and will be rigorously selected and closely supervised by the research team, the cognitive capacities of the older participants must be such that they can understand and answer the questionnaires properly. Finally, consistent with similar RCTs ${ }^{70}$ showing no difference between a social activity control group and a no-treatment control group with multiple long-term follow-up measures, and to reduce costs and logistical challenges, the present study includes only one control group.

\section{Author affiliations}

${ }^{1}$ Research Centre on Aging, Centre intégré universitaire de santé et de services sociaux (CIUSSS) de I'Estrie, Centre hospitalier universitaire de Sherbrooke (CHUS), Sherbrooke, Québec, Canada

${ }^{2}$ Faculty of Medicine and Health Sciences, Université de Sherbrooke, Sherbrooke, Quebec, Canada

${ }^{3}$ Research Centre, Institut universitaire de gériatrie de Montreal (CRIUGM), Montréal, Quebec, Canada

${ }^{4}$ School of Rehabilitation, Université de Montréal, Montréal, Quebec, Canada ${ }^{5}$ Research Centre, Charles-Le Moyne Hospital, Université de Sherbrooke Longueuil Campus, Longueuil, Quebec, Canada

${ }^{6}$ Department of Community Health Sciences, Université de Sherbrooke, Sherbrooke, Quebec, Canada

${ }^{7}$ Department of Social and Preventive Medicine, Laval University, Québec City, Quebec, Canada 
${ }^{8}$ Institute on Aging and Seniors' Social Participation, Saint-Sacrement Hospital, Québec City, Quebec, Canada

${ }^{9}$ Centre for Interdisciplinary Research in Rehabilitation of Greater Montreal,

Montreal, Quebec, Canada

${ }^{10}$ Faculty of Nursing, Université de Montréal, Montréal, Quebec, Canada

${ }^{11}$ French Institute of Transport, Development and Network Science and Technology (IFSTTAR), Marne-la-Vallée, France

${ }^{12}$ Hospital University of Bordeaux, Bordeaux, France

${ }^{13}$ Aix-Marseille University, Marseille, France

Acknowledgements The authors wish to thank Dr Jacques Lacroix, Janusz Kaczorowski and Andrée Sévigny for their questions and comments on a previous version of this protocol.

Contributors $M L$ prepared the first draft of this manuscript with the assistance of JL-B. All coauthors (M-FD, JF, H-MV, AT, M-JL, CG, HL, VB and CE) revised the manuscript and approved the final version.

Funding This work was supported by a Foundation Grant (\#148466) from the Canadian Institutes of Health Research (CIHR) and its publication by the Social Inequalities and Equity Strategic Grouping of the Quebec Population Health Research Network. ML is a Junior 1 Fonds de la recherche en santé du Québec (FRSQ) Researcher (salary award \#26815, 2013-2017) and a CIHR New Investigator (salary award \#360880, 2017-2022).

Competing interests None declared.

Patient consent Not required.

Ethics approval This study has been approved by the Research Ethics Committee of the CIUSSS de l'Estrie-CHUS (MP-31-2018-2424). The Committee will be notified of all substantial modifications to the protocol.

Provenance and peer review Not commissioned; externally peer reviewed.

Data sharing statement Data will be available upon request to corresponding author.

Open Access This is an Open Access article distributed in accordance with the Creative Commons Attribution Non Commercial (CC BY-NC 4.0) license, which permits others to distribute, remix, adapt, build upon this work non-commercially, and license their derivative works on different terms, provided the original work is properly cited and the use is non-commercial. See: http://creativecommons.org/ licenses/by-nc/4.0/

(C) Article author(s) (or their employer(s) unless otherwise stated in the text of the article) 2018. All rights reserved. No commercial use is permitted unless otherwise expressly granted.

\section{REFERENCES}

1. World Health Organization. "Ageing well" must be a global priority. 2014 http://www.who.int/mediacentre/news/releases/2014/lancetageing-series/en/.

2. Institut de la statistique du Québec. Québec survey on activity limitations, chronic diseases and aging, 2010-2011. Use of health and social services by people with a disability. $2013 \mathrm{http}: / / \mathrm{www}$. stat.gouv.qc.ca/statistiques/sante/services/incapacites/limitationmaladies-chroniques-utilisation-accessible.pdf (accessed Jun 2017)

3. Levasseur M, Richard L, Gauvin L, et al. Inventory and analysis of definitions of social participation found in the aging literature: proposed taxonomy of social activities. Soc Sci Med 2010;71:2141-9.

4. Maslow A. A symbol for holistic thinking. Persona 1947;1:24-5.

5. Holt-Lunstad J, Smith TB, Baker M, et al. Loneliness and social isolation as risk factors for mortality: a meta-analytic review. Perspect Psychol Sci 2015;10:227-37.

6. Cornwell EY, Waite LJ. Social disconnectedness, perceived isolation, and health among older adults. J Health Soc Behav 2009;50:31-48.

7. Holt-Lunstad J, Smith TB, Layton JB. Social relationships and mortality risk: a meta-analytic review. PLoS Med 2010;7:e1000316.

8. Leblanc M, Piché L, Arsenault S, et al. Pré-implantation de l'Accompagnement-citoyen personnalisé d'intégration communautaire (APIC): Adaptabilité, collaboration et financement, les déterminants d'une implantation réussie. Can J Aging 2017. In revision.

9. Butler SS. Evaluating the Senior Companion Program: a mixedmethod approach. J Gerontol Soc Work 2006;47:45-70.
10. Aubin G, Parisien M, Therriault PY. Développement de programmes visant à soutenir l'autonomie de l'intégration dans la communauté d'aînés ayant une problématique de santé mentale. Vie et vieillissement 2015:13:11-16.

11. Greaves CJ, Farbus L. Effects of creative and social activity on the health and well-being of socially isolated older people: outcomes from a multi-method observational study. J R Soc Promot Health 2006;126:134-42.

12. Raymond Émilie, Sévigny A, Tourigny A, et al. On the track of evaluated programmes targeting the social participation of seniors: a typology proposal. Ageing Soc 2013;33:267-96.

13. Raymond É, Sévigny A, Tourigny A, et al. Interventions évaluées visant la participation sociale des aînés. Fiches synthèses et outil d'accompagnement. $2015 \mathrm{http}: / /$ www.santecom.qc.ca/ Bibliothequevirtuelle/INSPQ/9782550734000.pdf.

14. Wong KC, Wong FKY, Yeung WF, et al. The effect of complex interventions on supporting self-care among community-dwelling older adults: a systematic review and meta-analysis. Age Ageing 2017;13:1-9.

15. Coll-Planas L, Nyqvist F, Puig T, et al. Social capital interventions targeting older people and their impact on health: a systematic review. J Epidemiol Community Health 2017;71:663-72.

16. McNamara B, Rosenwax L, Lee EA, et al. Evaluation of a healthy ageing intervention for frail older people living in the community. Australas J Ageing 2016;35:30-5.

17. Barnes M, Bennett G. Frail bodies, courageous voices: older people influencing community care. Health Soc Care Community 1998;6:102-11.

18. Cheung $\mathrm{C}-\mathrm{K}, \mathrm{Ngan} \mathrm{M}-\mathrm{H}$. Contributions of Volunteer Networking to Isolated Seniors in Hong Kong. J Gerontol Soc Work 2000;33:79-100.

19. Chan AW, Yu DS, Choi KC. Effects of tai chi qigong on psychosocial well-being among hidden elderly, using elderly neighborhood volunteer approach: a pilot randomized controlled trial. Clin Interv Aging 2017;12:85-96.

20. Stein SR, Linn MW, Weiner AS. Effectiveness of a Service Workers' Action Team (SWAT) for the elderly. J Am Geriatr Soc 1981;29:411-7.

21. Andersson L. Intervention against loneliness in a group of elderly women: an impact evaluation. Soc Sci Med 1985;20:355-64.

22. Fisher KJ, Li F, Michael Y, et al. Neighborhood-level influences on physical activity among older adults: a multilevel analysis. J Aging Phys Act 2004;12:45-63.

23. Routasalo PE, Tilvis RS, Kautiainen $\mathrm{H}$, et al. Effects of psychosocial group rehabilitation on social functioning, loneliness and well-being of lonely, older people: randomized controlled trial. J Adv Nurs 2009;65:297-305.

24. Kalson L. $M^{*} A^{*} S^{*} H$. A program of social interaction between institutionalized aged and adult mentally retarded persons. Gerontologist 1976;16:340-8.

25. Fried LP, Carlson MC, Freedman M, et al. A social model for health promotion for an aging population: initial evidence on the Experience Corps model. J Urban Health 2004;81:64-78.

26. Rook KS, Sorkin DH. Fostering social ties through a volunteer role: implications for older-adults' psychological health. Int J Aging Hum Dev 2003;57:313-37.

27. Wikström BM. Social interaction associated with visual art discussions: a controlled intervention study. Aging Ment Health 2002;6:82-7.

28. Clark F, Jackson J, Carlson M, et al. Effectiveness of a lifestyle intervention in promoting the well-being of independently living older people: results of the Well Elderly 2 Randomised Controlled Trial. $J$ Epidemiol Community Health 2012;66:782-90.

29. Lévesque MH, Sirois MJ, Trépanier J, et al. Effets et applicabilité en contexte québécois du Lifestyle Redesign chez les aînés [Impacts and applicability in Quebec context of the Lifestyle Redesign in older adults]. Can J Occup Ther 2016. In revision.

30. Bronfenbrenner U. Ecology of the family as a context for human development: Research perspectives. Dev Psychol 1986;22:723-42.

31. Seligman MEP. Positive Psychology, Positive Prevention, and Positive Therapy. In: Snyder CR, Lopez SJ, eds. Handbook of positive psychology. New York: Oxford University Press, 2002:3-9.

32. Carlson M, Clark F, Young B. Practical contributions of occupational science to the art of successful ageing: How to sculpt a meaningful life in older adulthood. J Occup Sci 1998;5:107-18.

33. Levasseur M, Lefebvre H, Levert M-J, et al. Adaptation of the Personalized citizen assistance for social participation (APIC) in older adults with disabilities: a feasible intervention to foster social and leisure activities in society. Health and Social Care in the Community 2017. Submitted.

34. Levasseur M, Lefebvre H, Levert MJ, et al. Personalized citizen assistance for social participation (APIC): A promising intervention 
for increasing mobility, accomplishment of social activities and frequency of leisure activities in older adults having disabilities. Arch Gerontol Geriatr 2016;64:96-102.

35. Lefebvre H, Levert M-J, Le Dorze G, et al. Un accompagnement citoyen personnalisé en soutien à l'intégration communautaire des personnes ayant subi un traumatisme craniocérébral: vers la résilience ? Rech Soins Infirm 2013;4:107-23.

36. Levert M-J, Gélinas I, Lefebvre H, et al. Citizen Assistance for Community Integration (APIC) in older adults with traumatic brain injury: an innovative intervention supporting social participation. Brain Inj Submitted.

37. Creswell JW. Research design: Qualitative, quantitative and mixed methods approaches. 2nd edn. Thousand Oaks, CA: Sage Publications, 2003.

38. Naud D, Levasseur M. Social participation and environmental barriers among aging Canadians: Distribution and differences in gender, age and location. Rowe KT, ed. Social isolation, participation and impact on mental health. Hauppauge, NY: Nova Science Publishers, Inc, 2015:1-21.

39. Levasseur M, Larivière $\mathrm{N}$, Royer $\mathrm{N}$, et al. Concordance entre besoins et interventions de participation des aînés recevant des services d'aide à domicile. Gérontologie et société 2012;35:111.

40. Levasseur $\mathrm{M}$, Larivière $\mathrm{N}$, Royer $\mathrm{N}$, et al. Match between needs and services for participation of older adults receiving home care. Leadersh Health Serv 2014;27:204-23.

41. Turcotte PL, Larivière N, Desrosiers $\mathrm{J}$, et al. Participation needs of older adults having disabilities and receiving home care: met needs mainly concern daily activities, while unmet needs mostly involve social activities. BMC Geriatr 2015;15:1.

42. Warburton J, McLaughlin D. Doing it from your heart: the role of older women as informal volunteers. J Women Aging 2006;18:55-72.

43. Drummond MF, Sculpher MJ, Claxton K, et al. Methods for the economic evaluation of health care programmes. 4th edn. Oxford, UK: Oxford University Press, 2015:445.

44. Zwarenstein M, Treweek S, Gagnier JJ, et al. CONSORT groupPragmatic Trials in Healthcare (Practihc) group. Improving the reporting of pragmatic trials: an extension of the CONSORT statement. BMJ 2008;337:a2390.

45. World Health Organization. Preamble to the Constitution of WHO. Geneva: World Health Organization, 1996.

46. Mills N, Blazeby JM, Hamdy FC, et al. Training recruiters to randomized trials to facilitate recruitment and informed consent by exploring patients' treatment preferences. Trials 2014;15:323.

47. Donovan JL, Athene Lane J, Peters TJ, et al. Development of a complex intervention improved randomization and informed consent in a randomized controlled trial. J Clin Epidemiol 2009;62:29-36.

48. Statistique Canada. Enquête sur la participation et les limitations d'activités de 2006: rapport analytique [Internet]. Ottawa: Statistique Canada, 2007:39. Report No.: 89-628-XIF.

49. Statistique Canada. Test du recensement 2008: rapport d'analyse du contenu. [Internet]. Ottawa: Statistique Canada, 2011:114. Report No.: 92-140-X.

50. Harris PA, Taylor R, Thielke $\mathrm{R}$, et al. Research electronic data capture (REDCap)--a metadata-driven methodology and workflow process for providing translational research informatics support. J Biomed Inform 2009;42:377-81.

51. Ware J, Kosinski M, Dewey J. How to Score Version 2 of the SF-36(r) Health Survey. Lincoln, RI: QualityMetric Incorporated, 2000.

52. Ware JE, Kosinski M. SF-36 Physical \& Mental Health Summary Scales: A Manual for Users of Version 1. 2nd edn. Lincoln, RI: QualityMetric, 2001:238.

53. Ware JE. SF-36 health survey update. Spine 2000;25:3130-.

54. McHorney CA, Ware JE, Lu JF, et al. The MOS 36-item ShortForm Health Survey (SF-36): III. Tests of data quality, scaling assumptions, and reliability across diverse patient groups. Med Care 1994;32:40-66.

55. Hayes V, Morris J, Wolfe C, et al. The SF-36 health survey questionnaire: is it suitable for use with older adults? Age Ageing 1995;24:120-5.

56. Gandek B, Sinclair SJ, Kosinski M, et al. Psychometric evaluation of the SF-36 health survey in Medicare managed care. Health Care Financ Rev 2004;25:5-25.

57. Gatchel RJ, Mayer T, Dersh J, et al. The association of the SF36 health status survey with 1 -year socioeconomic outcomes in a chronically disabled spinal disorder population. Spine 1999;24:2162-70.

58. Ware J, Snow K, Kosinski MA, et al. SF36 Health Survey: Manual and Interpretation Guide. Linc RI Qual Metr Inc 1993:30.

59. Hay J, LaBree L, Luo R, et al. Cost-effectiveness of preventive occupational therapy for independent-living older adults. J Am Geriatr Soc 2002:50:1381-8.

60. Richard L, Gauvin L, Kestens Y, et al. Neighborhood resources and social participation among older adults: results from the VoisiNuage study. J Aging Health 2013;25.

61. Richard L, Gauvin L, Gosselin C, et al. Staying connected: neighbourhood correlates of social participation among older adults living in an urban environment in Montreal, Quebec. Health Promot Int 2009;24:46-57.

62. Wood V, Wylie ML, Sheafor B. An analysis of a short self-report measure of life satisfaction: correlation with rater judgments. $J$ Gerontol 1969;24:465-9.

63. Régie de l'assurance maladie du Québec. Manuel des médecins omnipraticiens (No 100). 2016 http://www.ramq.gouv.qc.ca/ SiteCollectionDocuments/professionnels/manuels/100-facturationomnipraticiens/000_complet_acte_omni.pdf (accessed 1 Apr 2017).

64. Gouvernement du Québec. If you are receiving assistance: home care services and the service employment paycheque. $2009 \mathrm{http}: / /$ publications.msss.gouv.qc.ca/msss/fichiers/2008/08-513-02A.pdf (accessed 1 Apr 2017)

65. Hogue A, Henderson CE, Dauber S, et al. Treatment adherence, competence, and outcome in individual and family therapy for adolescent behavior problems. J Consult Clin Psychol 2008;76:544-55

66. Craig P, Dieppe P, Macintyre S, et al. Developing and evaluating complex interventions: the new Medical Research Council guidance. BMJ 2008;337:a1655.

67. Moore GF, Audrey S, Barker M, et al. Process evaluation of complex interventions: Medical Research Council guidance. BMJ 2015;350:h1258

68. Carroll C, Patterson M, Wood S, et al. A conceptual framework for implementation fidelity. Implement Sci 2007;2:40.

69. Breitenstein SM, Fogg L, Garvey C, et al. Measuring implementation fidelity in a community-based parenting intervention. Nurs Res 2010:59:158-65.

70. Clark F, Azen SP, Zemke R, et al. Occupational therapy for independent-living older adults. A randomized controlled trial. JAMA 1997;278:1321-6.

71. Machin D, Campbell M, Tan S, et al. Sample size tables for clinical studies. 3rd edn. Chichester, UK: Wiley-Blackwell, 2009.

72. Clark F, Azen SP, Carlson M, et al. Embedding health-promoting changes into the daily lives of independent-living older adults: longterm follow-up of occupational therapy intervention. J Gerontol B Psychol Sci Soc Sci 2001;56:P60-3.

73. Lajeunesse P. Personal communication, 2017.

74. Dubois M-F, Raîche M, Hébert R, et al. Assisted self-report of healthservices use showed excellent reliability in a longitudinal study of older adults. J Clin Epidemiol 2007:60:1040-5.

75. Kahan BC, Morris TP. Reporting and analysis of trials using stratified randomisation in leading medical journals: review and reanalysis. BMJ 2012;345:e5840.

76. Little RJA, Rubin DB. Statistical analysis with missing data. 2nd edn. Somerset, NJ: Wiley, 2002.

77. Hoch JS, Rockx MA, Krahn AD. Using the net benefit regression framework to construct cost-effectiveness acceptability curves: an example using data from a trial of external loop recorders versus Holter monitoring for ambulatory monitoring of "community acquired" syncope. BMC Health Serv Res 2006;6:68.

78. Miles M, Huberman M, Saldana J. Qualitative data analysis: a methods sourcebook. 3rd edn. Thousand Oaks, CA: Sage Publications, 2014

79. World Medical Association. World Medical Association Declaration of Helsinki: ethical principles for medical research involving human subjects. JAMA 2013;310:2191.

80. Clapperton I. La prévention pratico-pratique. Le Médecin du Québec 2005;40:33-9.

81. Foster N, Little P. Methodological issues in pragmatic trials of complex interventions in primary care. Br J Gen Pract 2012;62:10-11. 